\title{
Commentary: Cervical aortic arch repair-an overarching success
}

\author{
Jared P. Beller, MD, ${ }^{a}$ and Irving L. Kron, $\mathrm{MD}^{\mathrm{a}, \mathrm{b}}$
}

\footnotetext{
From the ${ }^{\mathrm{a} D i v i s i o n}$ of Thoracic and Cardiovascular Surgery, University of Virginia, Charlottesville, Va; and ${ }^{\mathrm{b}}$ Department of Surgery, University of Arizona Health Sciences, Tucson, Ariz. Disclosures: Authors have nothing to disclose with regard to commercial support.

Received for publication March 11, 2019; accepted for publication March 11, 2019; available ahead of print April $20,2019$.

Address for reprints: Irving L. Kron, MD, Department of Surgery, College of Medicine-Tucson, University of Arizona Health Sciences, 1501 N Campbell Ave, PO Box 245017, Tucson, AZ 85724 (E-mail: kron@email. arizona.edu).

J Thorac Cardiovasc Surg 2020;159:2214-5

$0022-5223 / \$ 36.00$

Copyright (c) 2019 by The American Association for Thoracic Surgery

https://doi.org/10.1016/j.jtcvs.2019.03.086
}

Cervical aortic arch (CAA) is a rare congenital malformation in which the aortic arch is located in an unusually high position above the clavicles. These are often asymptomatic and found incidentally but can cause compressive symptoms because aneurysmal growth might impinge on adjacent structures. Indications for surgery include aneurysm formation, coarctation, and compressive symptoms; however, management remains unstandardized because of the challenge associated with surgical intervention and the limited experience in the current literature.

In this issue of The Journal of Thoracic and Cardiovascular Surgery Zhong and colleagues ${ }^{1}$ provided the largest series to be published on this uncommon pathology with excellent outcomes and in doing so, have greatly contributed to the number of surgically treated patients presented in the literature. Their series includes 35 patients treated over a 7-year period with no mortality, stroke, or spinal cord injury. Moreover, rather than merely reporting operative outcomes they achieved $100 \%$, 1-year imaging follow-up and nearly half of patients had imaging available beyond 3 years. Approximately half of their patients presented symptomatically and an equal number of these CAAs were discovered incidentally and thus repaired prophylactically. Although they report aortic dimensions at follow-up, it would be interesting to note whether the asymptomatic, aneurysmal patients were monitored for growth, or repaired immediately, and at what aortic dimensions repair was performed.

Beyond collating an impressive number of cases of a rarely seen disease process, there are 2 other notable contributions of this report: (1) the variety of operative approaches and techniques required, and (2) a new classification system to facilitate discussion, operative planning, and categorization of CAA. Operations were performed either through a median sternotomy, or left or right thoracotomy and used a number of adjuncts including

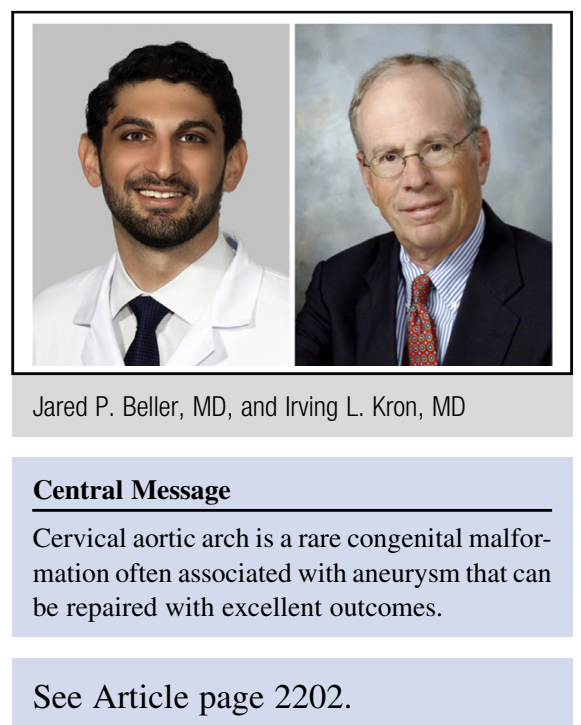

moderate hypothermic circulatory arrest at $25^{\circ} \mathrm{C}$ with selective antegrade cerebral perfusion. In contrast to the relatively straightforward repair of CAA with coarctation, CAA associated with aneurysm is significantly more challenging and surgeons attempting to tackle these complex operations need to be well versed in cerebral and spinal protection techniques to minimize morbidity.

Importantly, the authors propose a new classification system for these anomalies as a simplified schema compared with the traditional Haughton classification. ${ }^{2}$ In the proposed classification, aortic anatomy is first categorized by the absence or presence of a vascular ring and then further subdivided by the sidedness of the arch and descending aorta. Along with descriptions, the authors have provided clear anatomic diagrams of the potential branching patterns that one might encounter. However, as the authors discussed, tailoring the planned incision and operative approach to the individual patient anatomy is imperative because there is no standard configuration even within their proposed categories.

These excellent results show that challenging CAA repairs can be completed with minimal morbidity and mortality when performed by groups experienced with complex aortic arch reconstruction. Although the neuroprotective techniques used should be in the armamentarium of all cardiac surgeons, elective cases should be referred to aortic centers to ensure reproducible results with minimal morbidity. $^{3}$ 


\section{References}

1. Zhong YL, Ma WG, Zhu JM, Qiao ZY, Zheng J, Liu YM, et al. Surgical repair of cervical aortic arch: experience in 35 patients. J Thorac Cardiovasc Surg. 2020; 159:2202-13.e4.

2. Haughton VM, Fellows KE, Rosenbaum AE. The cervical aortic arches. Radiology. 1975;114:675-81.

3. Gazoni LM, Speir AM, Kron IL, Fonner E, Crosby IK. Elective thoracic aortic aneurysm surgery: better outcomes from high-volume centers. J Am Coll Surg. 2010;210:855-9. 